\author{
P. Angelini, E. Bricchi, N. Zeppilli, L. Dimitriu, M. Rondolini, G. Angeles, \\ S. Covino \& R. Venanzoni
}

\title{
Screening of the antifungal activity of essential oils against human and plant pathogenic filamentous fungi
}

\begin{abstract}
Angelini, P., Bricchi, E., Zeppilli, N., Dimitriu, L., Rondolini, M., Angeles, G., Covino, S. \& Venanzoni, R.: Screening of the antifungal activity of essential oils against human and plant pathogenic filamentous fungi. - Fl. Medit. 29: 5-12. 2019. — ISSN: 1120-4052 printed, 22404538 online.

In this study the antifungal activity of five essential oils (Canarium luzonicum, Cymbopogon martinii, Ledum palustre subsp. groenlandicum, Matricaria chamomilla, and Ocimum tenuiflorum) against both clinical (Penicillium chrysogenum, Aspergillus tubingensis, A. minutus) and plant pathogenic filamentous fungi (Verticillium spp., Fusarium oxysporum, Sclerotina sclerotiorum) were evaluated. Minimum Inhibitory Concentrations (MIC) were determined following CLSI M38-A2 recommendations.

All tested essential oils showed antifungal activity. C. martini and O. tenuiflorum essential oils were very effective with MIC range values similar or lower than those of terbinafine. Sclerotinia sclerotiorum (PeruMicA 26) and Verticillium spp. (PeruMicA 24) were the most sensitive strains to essential oils, while A. tubingensis (PeruMicA 21) showed the lowest sensitivity to the essential oils.
\end{abstract}

Key words: broth microdilution assay, drug resistance, MIC, natural products.

\section{Introduction}

There is an increasing consumer demand for natural preservatives to reduce the use of chemical compounds as antimicrobial agents in the field of nutrition and to combat various infections due to increasingly aggressive microorganisms that are resistant to the use of synthetic drugs (Melyssa \& al. 2014).

In this context, the use of plant derived substances, such as hydro-alcoholic extracts or essential oils, can certainly play a fundamental role. These substances have an enormous versatility, nowadays the same plant still represents an important pool for the identification of novel drug leads, with a very broad spectrum of action due to their different chemical structure (Atanasov \& al. 2015). 
One of the major problems of conventional medicine is the current, excessive use of synthetic antimicrobials, resulting in the hypersensitivity and toxicity of the drugs (Etebu \& Arikekpar 2016).

Pathogenic fungi can be the cause of fungal infections to which both humans and plants are susceptible, with some synthetic fungicides known to effectively control them. However, the emergence of resistant fungus strains limits the use of synthetic fungicides, with some of the latter possessing considerable toxicity. Moreover, the increased health and environmental hazard linked with synthetic molecules is of growing public concern. One of the most promising natural products for fungal inhibition can be found in essential oils (EOs) (Angelini \& al. 2018a). Intense antifungal properties have, in fact, been exhibited in many types of EOs obtained from different plants, bryophytes and fungi (Properzi \& al. 2013; Nazzaro \& al. 2017; Angelini \& al. 2014, 2016, 2017, 2018b; Dey \& Mukherjee 2015; Al-Fatimi \& al. 2018).

The composition, structure, and functional group of EOs have an important role in determining their biological activities. Their versatile character of antioxidant, antibacterial, antifungal, antidiabetic, antimutagenic and anticancer properties is well documented by many scientists (Angelini \& al. 2006; Tirillini \& al. 2009; Pagiotti \& al. 2012; Properzi \& al. 2013; Angelini \& al. 2018a).

In particular, the antimicrobial activity of plant oils and extracts has formed the basis of many applications, including raw and processed food preservation, pharmaceuticals, alternative medicine and natural therapies (Hammer \& al. 1999). The antimicrobial activity of essential oil might be caused by the properties of terpenes/terpenoids, that due to their highly lipophilic nature and low molecular weight are capable of disrupting the cell membrane, causing cell death or inhibiting the sporulation and germination of fungi.

While some of the EOs used on the basis of their reputed antimicrobial properties have well documented in vitro activity, there are few published data for many others (Tolouee \& al. 2010; Mishra \& Mishra 2011; Soni \& Soni 2014; Zhang \& al. 2017). Therefore, the aims of the current investigation were: i) to study the antifungal activity of Canarium luzonicum (Blume) A. Gray (Elemi, Burseraceae), Cymbopogon martini (Roxb.) W.Watson (Palmarosa, Poaceae), Ledum palustre subsp. groenlandicum (Oeder) Hultén (Ledum, Ericaceae), Matricaria chamomilla L. (Italian Camomilla, Lamiaceae) and Ocimum tenuiflorum L. (Tulsi, Lamiaceae) EOs against human and pathogenic filamentous fungi; ii) to verify the activity of the above-mentioned EOs against some fungal species resistant to common synthetic drugs.

\section{Materials and Methods}

\section{Essential oils}

The EOs used in this study were obtained from C. luzonicum, C. martinii, L. palustre subsp. groenlandicum, $M$. chamomilla and $O$. tenuiflorum. These oils were selected based on a literature survey due to being little known for their antifungal activity and were all bought from local markets. 


\section{Fungal strains}

In vitro antifungal activity of essential oils was assessed against six clinical [Aspergillus tubingensis (PeruMicA 21), A. minutus (PeruMicA 22), Penicillium chrysogenum (PeruMicA 23)] and plant pathogenic filamentous fungal strains [Verticillium spp. (PeruMicA 24), Fusarium oxysporum (PeruMicA 25), Sclerotina sclerotiorum (PeruMicA 26)].

Two yeast strains, Candida parapsilosis (ATCC 22019) and C. krusei (ATCC 6258), were used as quality controls (CLSI 2008; CLSI 2012; CLSI 2017) for antifungal assays.

Voucher microbial cultures are maintained in the PeruMycA culture collection of the Department of Chemistry, Biology and Biotechnology (DCBB) (University of Perugia, Italy) and are available upon request.

\section{Determination of Minimum Inhibitory Concentration (MIC)}

MIC was evaluated using the broth microdilution assay, according to the CLSI M38-A2 protocol (2008). The antifungal drug tested was terbinafine (Sigma-Aldrich, Milan, Italy). The medium used was RPMI (Roswell Park Memorial Institute) 1640 medium (Sigma) with L-glutamine and without sodium bicarbonate, supplemented with $2 \%$ glucose $(\mathrm{w} / \mathrm{v})$, buffered at $\mathrm{pH} 7.0$ with $0.165 \mathrm{M}$ morpholine propane sulfonic acid (MOPS buffer).

The fungal inoculum suspension was prepared using a spectrophotometer to match the optical density with that of $70 \%$ transmittance at a $530 \mathrm{~nm}$ wavelength. The final inoculum concentration was from 0.2 to $0.4 \times 10^{4-5} \mathrm{CFU} / \mathrm{ml}$.

Essential oils had a MIC range of 0.016-16 $\mu \mathrm{g} \mathrm{ml}^{-1}$ and terbinafine (Novartis, Basel, Switzerland) had a MIC range of $0.03-16 \mu \mathrm{g} \mathrm{ml}^{-1}$. MIC end-points ( $\mu \mathrm{g} \mathrm{ml}^{-1}$ ) were determined after 48 hours (for P. chrysogenum, A. tubingensis, A. minutus, Verticillium spp.) and 72 hours (for F. oxysporum, S. sclerotiorum) of incubation in ambient air at $28-30{ }^{\circ} \mathrm{C}$ (CLSI 2008; CLSI 2017).

For all tested EOs, the MIC end-points were defined as the lowest concentration that showed total growth inhibition (Pagiotti \& al. 2011). The MIC end-points for terbinafine were defined as the lowest concentration that inhibited $80 \%$ of the growth when compared with the growth control (Mota \& al. 2009).

Geometric means and MIC ranges were determined from the three biological replicates to allow comparisons between the activities of EOs.

\section{Results and discussion}

Recently, the scientific interest into antimicrobial properties of EOs has been increasing. In particular, a large number of papers have been published on the EOs antimicrobial activity, but many of them focused on the activity against bacteria and yeasts while little investigation on the effect of EOs against filamentous fungi has been performed (Angelini \& al. 2008, 2009; Khan \& al. 2010; Prasad \& al. 2010; Jamalian \& al. 2012; Nikolic \& al. 2016; Zhang $\&$ al. 2017). EOs from C. luzonicum, C. martinii, L. palustre subsp. groenlandicum, M. chamomilla and, O. tenuiflorum have been used for their medicinal properties for centuries; they 


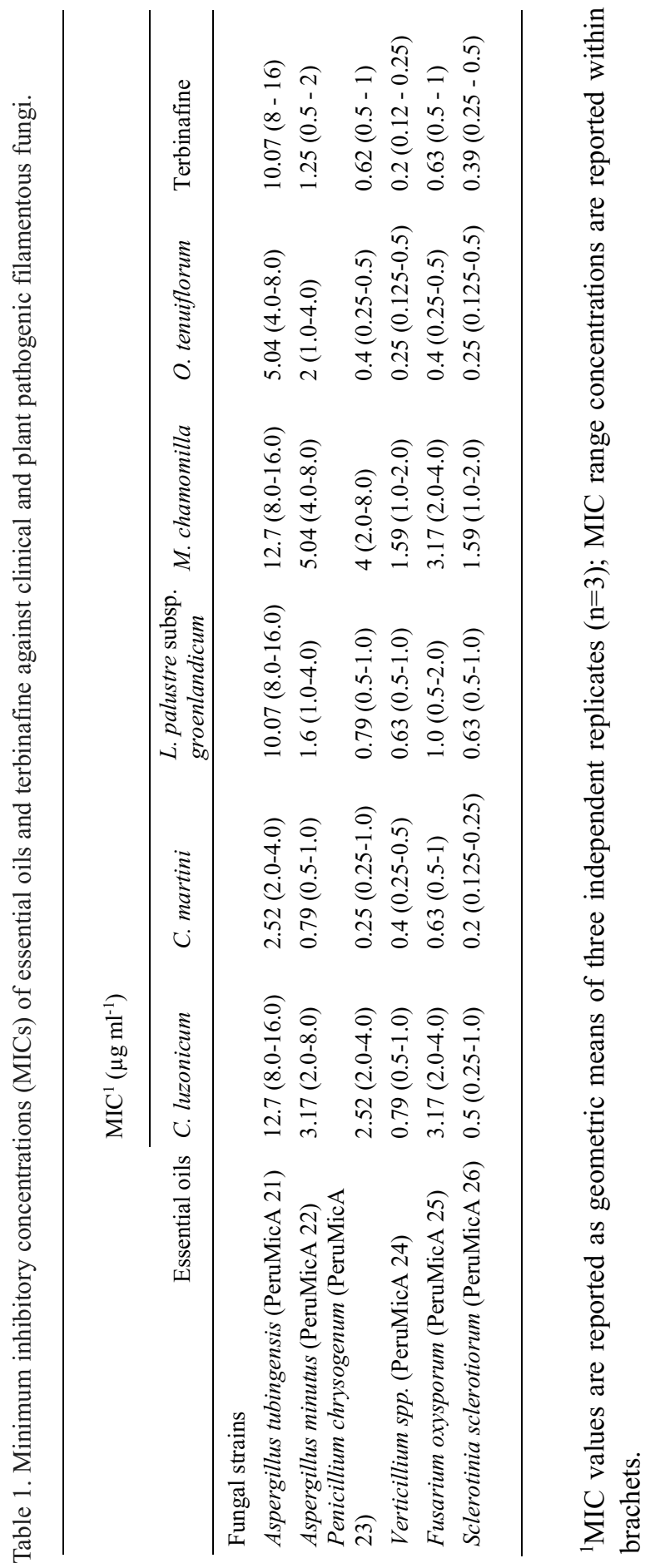


possess antibacterial, antifungal, antioxidant, and anti-inflammatory properties (Harris 2010; Mogana \& al. 2011; Singh \& al. 2011; Raut \& Karuppayil 2014; Yamani \& al. 2016).

In the present study, the antifungal activity of these five EOs against both clinical and plant pathogenic filamentous fungi were evaluated by CLSI document M38-A2 (2008).

\section{Antifungal activity of essential oils}

Table 1 shows the MIC ranges and geometric means of EOs and terbinafine against the fungal species which has been tested. The MIC values of quality control strains that were reproducible, fell within the established ranges published by CLSI protocol (2008). All tested EOs with concentrations ranging from 16-0.16 showed antifungal activity (Table 1). C. martini and O. tenuiflorum essential oils, were extremely effective on all tested fungi, with MIC range values similar or lower than those of terbinafine $\left(0.2-2.52 \mu \mathrm{ml}^{-1}\right.$ and $0.25-5.04 \mu \mathrm{m} \mathrm{m}^{-1}$ respectively), while $C$. luzonicum and $M$. chamomilla EOs exhibited a lower level of inhibition. The $S$. sclerotiorum and $V$. spp. strains tested demonstrated the most sensitive fungal species to essential oils, with MIC ranges of $0.125-2 \mu \mathrm{g} \mathrm{ml}^{-1}$, while $A$. tubingensis strain revealed the least sensitivity to the essential oils (MIC ranges: 2.52-12.7 $\mu \mathrm{g} \mathrm{ml}^{-1}$ ). Plant pathogens fungal strains were much more sensitive to terbinafine and essential oils than clinical strains (Table 1).

Terbinafine showed good activity in vitro against Verticillium spp. (MIC: $0.2 \mu \mathrm{g} \mathrm{ml}^{-1}$ ), $S$. sclerotiorum (MIC: $0.39 \mu \mathrm{g} \mathrm{ml}^{-1}$ ), P. chrysogenum (MIC: $0.62 \mu \mathrm{g} \mathrm{ml}^{-1}$ ), F. oxysporum (MIC range: $0.63 \mu \mathrm{g} \mathrm{ml}^{-1}$ ) while, $A$. minutus and A. tubingensis strains were less sensitive to this allylamine-antifungal drug, with a geometric MIC of $1.25-$ and $10 \mu \mathrm{g} \mathrm{ml}^{-1}$, respectively. Currently, clinically relevant breakpoints for terbinafine are not available. However, since for Ryder \& al. (1998) breakpoint of $>8 \mu \mathrm{g} / \mathrm{ml}$ was taken to indicate in vitro terbinafine resistance, $A$. tubingensis may be considered a fungal isolate terbinafine resistance.

A. tubingensis and A. minutus strains are also reported as amphotericin- and itraconazole-resistant (Pagiotti \& al. 2018).

\section{Conclusions}

This study provides a range of information about the antifungal activity of EOs of C. luzonicum, C. martini, L. palustre subsp. groenlandicum, M. chamomilla and, O. tenuiflorum. It is difficult to compare antifungal activity results from different studies because of the different extraction methods, test organisms and test systems used. Of the five EOs studied, C. luzonicum and C. martini were highly effective against all fungal strains tested, showing two promising sources in the search for new antifungal drugs. Moreover, most EOs are safe and free of adverse side effects when used properly.

The most important safety factor for EOs is their dosage (Edris 2007). Specific pharmacological approaches will be needed in future to validate its use as a phytotherapeutic product.

\section{References}

Al-Fatimi M., Wurster M. \& Lindequist U. 2016: Chemical composition, antimicrobial and antioxidant activities of the volatile oil of Ganoderma pfeifferi Bres. - Medicines 3(2): 10. https://doi.org/10.3390/medicines3020010. 
Angelini, P., Arcangeli, A., Bistocchi, G., Rubini, A., Venanzoni, R. \& Perini, C. 2017: Current knowledge of Umbrian macrofungi (central Italy). - Pl. Biosyst. 151(5): 915-923. https://doi.org/10.1080/11263504.2016.12656.

—, Bistocchi, G., Arcangeli, A., Rubini, A. \& Venanzoni, R. 2016: Inventory, diversity and communities of macrofungi in the Collestrada forest (Umbria, central Italy). - Pl. Biosyst. 150(5): 1096-1105. https://doi.org/10.1080/11263504.2015.1108939.

—, De Angelis, M. C., Guerzoni, R. P., Gigante, D., Rubini, A., Properzi A. \& Venanzoni R. 2014: Wood identification of pile dwellings from the Bronze Age San Savino site (Lake Trasimeno, central Italy). - Pl. Biosyst. 148: 713-722. https://doi.org/10.1080/11263504.2013.814604.

-, Granetti, B. \& Pagiotti, R. 2008: Effect of antimicrobial activity of Melaleuca alternifolia essential oil on antagonistic potential of Pleurotus species against Trichoderma harzianum in dual culture. - World J. Microb. Biotech. 24: 197-202. https://doi.org/ 10.1007/s11274-007-9456-x.

—, Pagiotti, R., Menghini, A. \& Vianello, B. 2006: Antimicrobial activities of various essential oils against foodborne pathogenic or spoilage moulds. - Ann. Microbiol. 56(1): 65-69. https://doi.org/10.1007/BF03174972.

_, - , Venanzoni, R. \& Granetti, B. 2009: Antifungal and allelopathic effects of Asafoetida against Trichoderma harzianum and Pleurotus spp. - Allelopathy J. 23(2): 357-368. ISSN 0971-4693.

—, Tirillini, B., Akhtar, M. S., Dimitriu, L., Bricchi, E., Bertuzzi, G. \& Venanzoni, R. 2018a: Essential oil with anticancer activity: an overview. - Pp. 207-231, in: Akhtar, M. S. \& Swamy, M. K. (eds.), Anticancer Plants: Natural Products and Biotechnological Implements. Springer, Singapore. https://doi.org/10.1007/978-981-10-8064-7_9

-, 一, Bistocchi, G., Arcangeli, A., Rubini, A., Pellegrino, R. M., Fabiani, R., Cruciani, G., Venanzoni, R. \& Rosignoli, P. 2018b: Overview of the biological activities of the methanolic extract from wild Fomitopsis pinicola fruiting body from Central Italy. - I.J.M.M. 20(11): 1047-1063. https://doi.org/ 10.1615/IntJMedMushrooms.2018028595.

Atanasov, A. G., Waltenberger, B., Pferschy-Wenzig, E. M., Linderd, T., Wawrosch, C., Uhrin, P., Temml, V., Wang, L., Schwaiger, S., Heiss, E. H., Rollinger, J. M., Schuster, D., Breuss, J. M., Bochkov, V., Mihovilovic, M. D., Kopp, B., Bauer, R., Dirsch, V. M. \& Stuppner, H. 2015: Discovery and resupply of pharmacologically active plant-derived natural products: a review. - Biotechnol. Adv. 33(8): 1582-1614. https://doi.org/10.1016/j.biotechadv.2015.08.001.

CLSI 2008: Reference method for broth dilution antifungal susceptibility testing of filamentous fungi; approved standard-second edition. CLSI document M38-A2. - Wayne.

- 2012: Reference method for broth dilution antifungal susceptibility testing of yeasts; 4th informational supplement. CLSI document M27-S4. - Wayne.

- 2017: Performance standards for antifungal susceptibility testing of filamentous fungi. 1st. ed. CLSI supplement M61. - Wayne.

Dey, A. \& Mukherjee, A. 2015: Therapeutic potential of bryophytes and derived compounds against cancer. - J. Acute Dis. 4(3): 236-248. https://doi.org/10.1016/j.joad.2015.04.011.

Edris, A. E. 2007: Pharmaceutical and therapeutic potentials of essential oils and their individual volatile constituents: a review. - Phytother. Res. 21(4): 308-323. https://doi.org/10.1002/ptr.2072

Etebu, E. \& Arikekpar, I. 2016: Antibiotics: classification and mechanisms of action with emphasis on molecular perspectives. - I.J.A.M.B.R. 4: 90-101. ISSN 2053-1818.

Hammer, K. A., Carson, C. F. \& Riley, T. V. 1999: Antimicrobial activity of essential oils and other plant extracts. - J. Appl. Microbiol. 86(6): 985-90. https://doi.org/10.1046/j.13652672.1999.00780.

Harris, R. 2010: Phytotherapeutic uses of essential oils. - Pp 315-351, in: Baser, K. H. C., Buchbauer, G. (eds), Handbook of essential oils: Science, technology and applications. - Boca Raton, London, New York 
ISO. 2018. International Standards Organisation - Home Page. - http://www.iso.org/home.htm [Last Accessed 26 October 2018]

Jamalian, A., Ghahfarokhi, M. S., Jaimand, K., Pashootan, N., Amani, A. \& Razzaghi-Abyaneh, M. 2012: Chemical composition and antifungal activity of Matricaria recutita flower essential oil against medically important dermatophytes and soil-borne pathogens. - J. Mycol. Méd. 22(4): 308-315. https://doi.org/10.1016/j.mycmed.2012.09.003

Khan, A., Ahmad, A., Manzoor, N. \& Khan, L. A. 2010: Antifungal activities of Ocimum sanctum essential oil and its lead molecules. - Nat. Prod. Commun. 5(2): 345-349. ISSN 1934-578X.

Melyssa, N., Tânia, P. S., Cristiane, S. S. M., Isis, R. G. C., Terezinha, I. E. S. \& Erika, S. K. 2014 : Early state research on antifungal natural products. - Molecules 19: 2925-2956. https://doi.org/10.3390/molecules19032925.

Mishra, P. \& Mishra, S., 2011: Study of antibacterial activity of Ocimum sanctum extract against Gram positive and Gram negative bacteria. - Amer. J. Food Techn. 6(4): 336-341. https://doi.org/10.3923/ajft.2011.336.341.

Mogana, R. \& Wiart, C. 2011: Canarium L.: a phytochemical and pharmacological review. - J. Pharm. Res. 4(8): 2482-2489. ISSN: 0974-6943.

Mota, C. R., Miranda, K. C., Lemos, J. de A., Costa, C. R., Hasimoto-Souza, L. K., Passos, X. S., Meneses-Silva, H. \& Silva, M. do R. 2009: Comparison of in vitro activity of five antifungal agents against dermatophytes, using the agar dilution and broth microdilution methods. - Rev. Soc. Bras. Med. Trop. 42: 250-254. http://dx.doi.org/10.1590/S0037-86822009000300003.

Nazzaro, F., Fratianni, F., Raffaele, Coppola, R. \& De Feo, V. 2017: Essential oils and antifungal activity. - Pharmaceuticals 10(4): pii:E86. http://dx.doi.org/10.3390/ph10040086.

Nikolić, M, Smiljković, M., Marković, T., Ćirić, A., Glamoclija, J., Marković, D. \& Soković, M. 2016: Sensitivity of clinical isolates of Candida to essential oils from Burseraceae family. EXCLI J. 15: 280-289. http://dx.doi.org/10.17179/excli2014-621.

Pagiotti, R., Angelini, P., Rubini, A., Tirillini, B., Granetti, B. \& Venanzoni, R. 2011: Identification and characterisation of human pathogenic filamentous fungi and susceptibility to Thymus schimperi essential oil. - Mycoses 54: e364-376. http://dx.doi.org/10.1111/j.14390507.2010.01926.x.

Prasad, C. S., Shukla, R., Kumar, A. \& Dubey, N. K. 2010. In vitro and in vivo antifungal activity of essential oils of Cymbopogon martini and Chenopodium ambrosioides and their synergism against dermatophytes. - Mycoses 53(2): 123-129. http://dx.doi.org/10.1111/j.14390507.2008.01676.x.

Properzi, A., Angelini, P., Bertuzzi, G. \& Venanzoni, R. 2013: Some biological activities of essential oils. - Med. Aromat. Pl. 2: 136. http://dx.doi.org/10.4172/2167-0412.1000136.

Raut, J. S. \& Karuppayil, S. M., 2014: A status review on the medicinal properties of essential oils. - Ind. Crops Prod. 62: 250-264. http://dx.doi.org/10.1016/j.indcrop.2014.05.055.

Ryder, N. S., Wagner, S. \& Leitner, I. 1998: In vitro activities of terbinafine against cutaneous isolates of Candida albicans and other pathogenic yeasts. Antimicrob. - Agents Chemother. 42(5): 1057-1061. http://dx.doi.org/10.1128/AAC.42.5.1057.

Singh, O., Khanam, Z., Misra, N. \& Srivastava, M. K. 2011: Chamomile (Matricaria chamomilla L.): an overview. - Pharmacogn. Rev. 5(9): 82-95. http://dx.doi.org/10.4103/09737847.79103 .

Soni, S. \& Soni, U. N. 2014. In vitro anti-bacterial and anti-fungal activity of select essential oils. Int. J. Pharm. Pharm. Sci. 6(6): 586-591.

Tirillini, B., Pagiotti, R., Angelini, P., Pintore, G., Chessa, M. \& Menghini, L. 2009: Chemical composition and fungicidal activity of the essential oil of Laserpitium garganicum from Italy. Chem. Nat. Compd. 45(1): 103-105. https://doi.org/10.1007/s10600-009-9237-x 
Tolouee, M., Alinezhad, S., Saberi, R., Eslamifar, A., Zad, S. J., Jaimand, K., Taeb, J., Rezaee, M. B., Kawachi, M., Shams-Ghahfarokhi, M. \& Razzaghi-Abyaneh, M. 2010: Effect of Matricaria chamomilla $\mathrm{L}$. flower essential oil on the growth and ultrastructure of Aspergillus niger van Tieghem. - Int. J. Food Microbiol. 139: 127-133. https://doi.org/10.1016/j.ijfoodmicro.2010.03.032.

Yamani, H. A., Pang, E. C., Mantri, N., Margaret, A. \& Deighton, M. A. 2016: Antimicrobial activity of Tulsi (Ocimum tenuiflorum) essential oil and their major constituents against three species of bacteria. - Front. Microbiol. 7: 681. https://doi.org/10.3389/fmicb.2016.00681

Zhang, L., Wang, Y., Xu, M. \& Hu, X. 2017: Chemical composition and antibacterial activity of the essential oil from Chinese wild Ledum palustre L. on Vibrio parahaemolyticus. - Int. J. Food Nutr. Sci. 4(1): 8-12. https://doi.org/10.15436/2377-0619.17.1270

Addresses of the authors:

Paola Angelini ${ }^{1}$, Emma Bricchi ${ }^{1}$, Nalita Zeppillii ${ }^{1}$, Luminita Dimitriu ${ }^{2}$, Mara Rondolini ${ }^{1}$, Giancarlo Angeles ${ }^{1}$, Stefano Covino ${ }^{1} \&$ Roberto Venanzoni $^{1}$,

${ }^{1}$ Department of Chemistry, Biology and Biotechnology, University of Perugia, via del Giochetto - 06123 Perugia, Italy. E-mail: paola.angelini@unipg.it

${ }^{2}$ Faculty of Biotechnology, University of Agricultural Sciences and Veterinary Medicine of Bucharest, Bucharest, Romania. 